\title{
VISITANTES, AUDIENCIAS, PÚBLICOS. APUNTES PARA UN ESTUDIO DESDE LAS PRÁCTICAS CULTURALES*
}

\author{
VISITORS, AUDIENCES, AND THE PUBLIC: NOTES FOR A \\ STUDY FROM THE PERSPECTIVE OF CULTURAL PRACTICES
}

\section{CARLA PINOCHET C.**, PEDRO GÜELL V.***}

RESUMEN: A partir de una revisión de las principales corrientes que han experimentado los estudios de público, con énfasis en el ámbito de los museos de arte, este artículo busca reflexionar acerca de los principios que han guiado la conceptualización de los públicos, la metodología que se ha implementado para registrar sus experiencias, y los supuestos problemáticos que han obstaculizado su desarrollo. Se propone, a partir de estos análisis, que los públicos culturales deben ser abordados desde un enfoque procesual, capaz de captar los modos complejos y diversos en que los sujetos y comunidades interactúan con los productos culturales.

Palabras clave: Estudios de públicos, estudios de audiencia, consumo cultural, prácticas culturales.

AвSTRACT: Reviewing the main trends in research on visitor experiences, with an emphasis on art museums, this article seeks to reflect on the principles that shape the conceptualization of the public, the methodology used to register its experiences, and the problematic assumptions that impede its development. This analysis provides support for the claim that audiences should be studied from a processual perspective capable of registering the complex and diverse ways in which individuals and communities interact with cultural products.

KEYWORDS: Visitor studies, audience studies, cultural consumption, cultural practices.

Recibido: 05.04.17. Aceptado: 30.11.17.

* Artículo escrito en el marco del Proyecto Fondecyt de Postdoctorado 3150105, "Sociabilidad y co-producción de la experiencia cultural en el espacio público urbano: las ferias y festivales culturales de la zona central de Chile" (2014-2017). Investigadora responsable: Carla Pinochet Cobos.

** Doctora en Ciencias Antropológicas. Universidad Alberto Hurtado, Santiago, Chile. Correo electrónico: carlaasecas@gmail.com

*** Doctor en Sociología. Universidad Alberto Hurtado, Santiago, Chile. Correo electrónico: pguellv@gmail.com 
Z N el ámbito de la cultura, los llamados estudios de público han Crecorrido un auspicioso camino desde sus inicios hace al menos tres décadas. Hoy tenemos más y mejor información sobre la forma en que las personas acceden y se apropian de las ofertas culturales, pero también se han vuelto evidentes las limitaciones de este tipo de estudios. Si bien la capacidad de capturar información y las herramientas metodológicas son más sofisticadas, las investigaciones en torno a los públicos aún se concentran mayoritariamente en medir frecuencias de acceso a la cultura y explicarlas según las características sociodemográficas de los individuos. En este texto, sostenemos que este enfoque muestra dificultades para responder a los desafíos que conlleva la permanente transformación de los consumos culturales, al vaivén de los cambios sociales y subjetivos de nuestros tiempos.

Esta dificultad no tiene sus raíces en un asunto estrictamente metodológico, sino más bien en un problema teórico y normativo. Revisaremos, en consecuencia, cuáles han sido los supuestos sobre los que han descansado los estudios de visitantes, audiencias y públicos de museos, avanzando hacia una problematización de estos fenómenos centrada en las prácticas culturales. Ello podría permitir una aproximación más comprensiva hacia dos desafíos cruciales e insuficientemente abordados en los estudios de públicos: por una parte, reconstruir la forma en que las audiencias hacen experiencias culturales, y por la otra, evaluar el impacto personal y social de esas experiencias.

\section{1. ¿CÓMO DEFINIR LOS PÚBLICOS CULTURALES?}

Desde las miradas más románticas a las más pragmáticas, todas las perspectivas que se han propuesto estudiar las audiencias culturales coinciden en que los públicos contemporáneos son muchos y diferentes entre sí (Cimet, 1987; Heinich, 2001; Schmilchuk, 2012; García Blanco, Pérez Santos y Andonegui, 1999; Garde y Varela, 2010). Sin embargo, en sus intentos por caracterizar esa diversidad y explicar su origen, estas aproximaciones exhiben formas diferentes y hasta encontradas de entender e imaginar a quienes participan de las actividades de la cultura. ¿Cómo se han entendido y definido los públicos hasta la fecha?

A partir de un análisis del abanico de aproximaciones contemporáneas a los públicos culturales, especialmente de museos, se puede establecer una distinción entre tres lógicas que predominan en los debates especializados. En cada una de ellas es posible reconocer un modo de conceptualizar los 
públicos, y una serie de supuestos respecto de sus características y de los criterios adecuados para medirlos y clasificarlos. Estos modelos ideales pocas veces se presentan puros y aislados; en las iniciativas y políticas culturales específicas estas ópticas conviven, compiten y se complementan.

\section{a. Los públicos como educandos}

Podemos remontar los orígenes de este primer modelo de públicos al proyecto civilizatorio sobre el que las naciones modernas -desde fines del siglo XVIII, en muchos países europeos; y desde fines del XIX, en América Latina- intentaron edificar sus cimientos. Esta primera vocación de las políticas culturales, movilizada desde las escuelas y los incipientes museos, consideró los bienes simbólicos como vehículos privilegiados para la transmisión de los valores que se consideraban superiores y trascendentes, y que fundaban la cohesión social (Castilla, 2010; Yúdice y Miller, 2004; Iregui, 2008). Este proceso de "educación del gusto" de la amplia población nacional descansa, por una parte, en una supuesta "incompletitud ética" de los ciudadanos y, por la otra, en su carácter de receptor pasivo de aquellos contenidos y valores que provienen de la autoridad moral y educativa.

Hoy en día, "formar" a los públicos en buena medida sigue significando proporcionarles ciertas herramientas que no poseen, y que son cruciales para acceder a bienes y experiencias que se asumen como beneficiosos. El público se imagina, entonces, como un receptor, cuyo papel es absorber -más o menos pasivamente, y a partir de una transmisión relativamente vertical- un repertorio de valores, actitudes, conocimientos y experiencias que desconocía hasta entonces, y que son provechosos para su espíritu y/o para el desarrollo social.

La agenda de este tipo de políticas se concentra en el acceso a la cultura por parte de los sectores menos favorecidos de la sociedad y en el control de la calidad "educativa" de los bienes culturales ofrecidos. La noción de "democratización de la cultura", entendida como superación de las barreras de acceso, se ha apoyado en esta tradición educativa, resignificando la noción de la cultura como don para pasar a entenderla como un derecho (Rosas Mantecón, 2007). Esta idea de los públicos centrada en el acceso ha constituido el motor principal de los primeros estudios, cuyas mediciones se concentran en las variables sociodemográficas de la exclusión cultural ${ }^{1}$.

\footnotetext{
${ }^{1}$ Principalmente referidas a edad, sexo, origen geográfico, nivel social, nivel de estudios e ingresos.
} 


\section{b. Los públicos como clientes}

En el marco de transformaciones globales que vienen reconfigurando las condiciones de producción, circulación y distribución de los bienes simbólicos, la oferta cultural ha sido crecientemente asimilada a la industria del entretenimiento (Huyssen, 1994). De este modo, mientras los espacios e instituciones artísticas comienzan a ser entendidos como "prestadores de servicios culturales", un nuevo discurso acerca de los públicos adquiere fuerza: aquel que visualiza a los usuarios de la infraestructura cultural como clientes. Cuando la lógica del consumidor reemplaza a la del educando, los públicos de la cultura son imaginados desde coordenadas políticas diferentes. Los servicios culturales entregados a los visitantes ya no buscan habilitarlos para un ejercicio más pleno de sus derechos ciudadanos, sino responder a sus exigencias, expectativas y capacidades de demanda. Desde el primer modelo de públicos, las cifras de asistencia a los eventos culturales permitían elaborar juicios acerca del nivel de "alfabetismo cultural" de la población. Desde esta nueva óptica, en cambio, el problema comienza a ser de las instituciones culturales, ya que las cifras de asistencia se entienden como un reflejo directo de la capacidad de estas para atraer, fidelizar y satisfacer a los visitantes (Garde y Varela, 2010).

Desde esta perspectiva, los públicos son imaginados como sujetos que demandan y deben ser complacidos, de la misma forma que la oferta cultural debe constituir una experiencia generadora de utilidad para el visitante. La pasividad que caracteriza al educando no se ve revertida, puesto que el cliente continúa siendo el receptor de una producción cultural externa, que ya no se recibe como regalo, sino como adquisición. El criterio fundamental para medir y evaluar los públicos es el volumen, aunque también resulten de utilidad otros elementos cualitativos que hacen posible diversificarlos (hacia el no público), ampliarlos (hacia el público ocasional) y sostenerlos en el tiempo (fidelizando al público cautivo). En esta línea, algunos autores han indagado en tiempos recientes en la elaboración de métricas más complejas que permitan demostrar el éxito de las iniciativas culturales más allá de la cantidad de boletos emitidos, intentando aprehender procesos altamente subjetivos como la satisfacción o la experiencia de visita (Ojeda Sánchez, 2008; Anderson, 2004; Fox, 2006).

\section{c. Los públicos como interlocutores}

Un tercer discurso sobre los públicos se alimenta de una gama heterogénea de procesos sociales, en todos los cuales se manifiesta la creciente impor- 
tancia de la cultura en la mediación entre diferentes y como espacio de participación ciudadana. Si el primer modelo se sustentaba en una direccionalidad única entre los emisores y los receptores; y el segundo privilegiaba las demandas de los consumidores en la definición de las ofertas culturales; esta última perspectiva busca constituir una relación de ida y vuelta entre los públicos y los productores del campo de la cultura. Se apela, entonces, a los públicos como participantes creativos de la cultura en tanto espacio de diálogo y encuentro (Holo y Álvarez, 2011).

Al menos tres procesos simultáneos han ejercido una influencia directa sobre esta tercera forma de definir a los públicos. En primer término, el afianzamiento de la acepción antropológica de la cultura en el ámbito de las políticas culturales (Wimmer y Vericat, 2000; Hannerz, 1996). Destacando el carácter conformador de los modos de vida que tienen los medios simbólicos, esta noción amplia de la cultura instituye la idea de que todos tienen cultura, y que toda cultura tiene un similar valor expresivo. Así, entendiendo a los públicos a partir de sus pertenencias colectivas, según esta perspectiva, las políticas culturales deben facilitar el reconocimiento y promoción de los acervos culturales de sus beneficiarios mediante formas de diálogo bidireccional (Ochoa, 2003). En segundo lugar, el carácter creativo y participativo de los públicos ha sido subrayado desde los propios productores artísticos, quienes han desarrollado una conciencia explícita acerca de la capacidad de las audiencias de completar y dar sentido a las obras, pasando en muchos casos a ser parte constitutiva de estas (Olivera, 2011).

Finalmente, un tercer proceso que ha contribuido a visibilizar la agencia de los públicos culturales son las transformaciones culturales y tecnológicas, que permiten grados inéditos de conexión, interactividad y comunicación (García Canclini, 2004). Hoy resulta más fácil rastrear las reverberaciones que tienen las producciones artísticas a través de internet y las redes sociales, evidenciando las múltiples formas de apropiación de las obras. Los espectadores contemporáneos demandan nuevos canales de participación e interacción con las producciones culturales que consumen, difuminando cada vez más las fronteras entre la producción y el consumo de arte y cultura.

Cada uno de estos modos de entender a los públicos ilumina ciertas dimensiones, pero la vez oscurece otras. La concepción de los públicos como educandos suele desconocer los márgenes de acción creativa de los sujetos a quienes se dirigen las políticas culturales, invisibilizando de esta manera el valor de sus creaciones simbólicas. La lógica de los públicos como clientes, por su parte, no dispone de herramientas para observar críticamente los 
procesos de construcción de demandas culturales en la sociedad de consumo. Esto no solo afecta la posibilidad de hacer de la cultura un espacio de deliberación democrática; también puede significar la restricción de espacio de la innovación, que normalmente florece al margen de las grandes corrientes de la demanda. Finalmente, al modelo idealista de los públicos como interlocutores de un diálogo plural y horizontal le cuesta reconocer las profundas asimetrías en el acceso y uso de los espacios y aparatos de la creación y el intercambio cultural.

\section{2. ¿CÓMO ESTUDIAR LOS PÚBLICOS CULTURALES?}

En el amplio espectro de actividades culturales contemporáneas, y de forma especial en el ámbito de los museos, la preocupación por conocer los públicos y sus motivaciones ha dado lugar a un número importante de estudios, configurando un campo de investigación en sí mismo (visitorstudies, audiencesresearch). En línea con cierta literatura reciente que ha intentado examinar estas aproximaciones sostenemos que los investigadores de los públicos han optado por dar respuesta a una de tres tipos de pregunta. Examinaremos sus características, implicancias y métodos privilegiados.

\section{a. ¿Qué factores determinan el acceso a los bienes y servicios culturales?}

Las primeras investigaciones en torno al consumo cultural se originaron tratando de responder este tipo de interrogante: ya en los años sesenta, los aportes cruciales de Pierre Bourdieu dieron cuenta de la correlación determinante que se establece entre la estratificación sociocultural y el acceso a los bienes artísticos y culturales, señalando que las desigualdades no solo descansan en una diferencia económica, sino que -sobre todo-responden a un habitus de clase que incide directamente en la formación del gusto y en el desarrollo del "amor al arte" (Bourdieu, 2012; Bourdieu y Darbel, 2003). La evidencia incontrovertible de la relación entre capital económico y capital cultural marcó la vocación de los estudios que le sucedieron, los cuales han hecho de los aspectos sociodemográficos la principal variable explicativa del acceso desigual a los bienes y experiencias culturales.

Diversos investigadores han incorporado en las últimas décadas otro tipo de factores también relacionados con el acceso / no acceso a estas formas de consumo, que complejizan la explicación sociodemográfica con elementos motivacionales y subjetivos (Hood, 1986; Rosas Mantecón, 
2007; Schmilchuk, 2012²). Casi siempre, estos estudios buscan acompañar la "democratización" de la cultura, identificando los sectores excluidos del consumo cultural y diseñando estrategias para trabajar sobre los factores de marginación. Las metodologías privilegiadas para este tipo de aproximaciones han sido eminentemente cuantitativas, valiéndose de encuestas y cuestionarios sistematizables. En menor medida, se han aplicado entrevistas estructuradas con el propósito de reconstruir patrones individuales de consumo cultural, las cuales han demostrado cierta utilidad al cruzar los datos obtenidos con la información proveniente de las taquillas.

Sostenemos que una buena manera de pensar la pregunta por el acceso es referirla a la noción de visitantes: el conjunto de personas que acceden efectivamente a los bienes, espacios y tiempos de las ofertas culturales, sus usuarios. Afirmamos que este primer tipo de estudios hace de los visitantes su ámbito de indagación, distinguiéndolos de quienes no pueden acceder a la oferta cultural y caracterizándolos en términos de las frecuencias de sus consumos y del tipo de bienes a los que acceden. Las investigaciones de visitantes, casi siempre al servicio de las necesidades institucionales, se concentran en los factores sociodemográficos que facilitan o dificultan el acceso al consumo cultural, y en consecuencia, no consideran las experiencias que constituyen a los sujetos ni el efecto ulterior que tienen sus visitas.

\section{b. ¿Qué perfiles podemos distinguir dentro de quienes acceden a los bienes culturales?}

Un segundo tipo de preguntas que ha convocado los estudios de público ha restringido su mirada a los espacios efectivos del consumo cultural, generando tipologías dentro de las audiencias para identificar los modos diversos en que los sujetos se relacionan con la oferta cultural. Estos estudios detienen la atención en dos aspectos que caracterizan a los usuarios de las instalaciones culturales: los elementos motivacionales -es decir, aquellos que son previos a la visita-, y los elementos relativos a la experiencia -tanto objetivos como subjetivos (Verón y Levasseur, 1991; Pérez Santos, 2008). Muchas de estas investigaciones consideran ambos aspectos, correlacio-

\footnotetext{
${ }^{2}$ Por ejemplo, algunos de estos estudios han demostrado cómo las dificultades en la identificación de ciertos monumentos o espacios patrimoniales inciden en la participación cultural de los públicos. Otros han intentado quebrar con el criterio binario que distingue de antemano entre públicos y no públicos culturales, incorporando variables psicográficas de los visitantes para analizar las opciones de actividades culturales dentro de un amplio rango de posibilidades disponibles para ocupar el tiempo libre (Hood, 1986).
} 
nando las expectativas y las formas de experiencia. Las metodologías que han demostrado una mayor capacidad explicativa han sido las de carácter cualitativo, y en la mayoría de los casos se limitan a examinar con cierta profundidad una o dos experiencias culturales. Entre las técnicas más socorridas están las etnografías, las entrevistas en profundidad y los estudios de impacto.

Sin embargo, el alcance de estas preguntas y metodologías es, aún, muy limitado. Aunque estos estudios se preguntan por la interacción de los visitantes con los bienes y servicios culturales, en la mayor parte de los casos se trata de indagaciones breves y específicas que no han logrado proyectar sus exploraciones a la oferta cultural general. Este carácter localista y la desarticulación de estas tentativas exploratorias no han permitido establecer parámetros de comparación entre unas experiencias y otras, ni dar continuidad a este tipo de estudios e indagaciones.

Así como en el primer caso observamos la existencia de un conjunto de estudios sobre los visitantes, distinguimos en este segundo tipo un objeto de análisis diferente, que nombraremos como audiencias culturales. El estudio de las audiencias parte de la idea de que son las personas concretas las que acceden a las obras, y que se deben investigar justamente esas experiencias e interacciones. Para avanzar en la democratización de la cultura no basta con facilitar las condiciones de acceso físico a la oferta cultural, sino que se requiere poder establecer una comunicación subjetiva con ella. La noción de audiencias, por lo tanto, entiende a los sujetos que las conforman como intérpretes y receptores, instalando una pregunta acerca de los modos de apropiación subjetiva. Así entendidos, los estudios de las audiencias investigan la capacidad que tienen los sujetos para apropiarse del mensaje de las obras y los valores que guían esa apropiación.

\section{c. ¿Cómo se relaciona la experiencia de consumo de bienes y servicios culturales con procesos más amplios de construcción de la identidad?}

Finalmente, es posible identificar un tercer tipo de pregunta que avanza en especificidad y complejidad respecto de las interrogantes anteriores. Esta se cuestiona no solo quiénes pueden acceder al consumo cultural, cuáles son sus motivaciones para hacerlo y cómo se comportan en el momento de la visita, sino qué es lo que los sujetos hacen con aquello que adquirieron en dicha experiencia. Una pregunta así formulada descansa en una noción procesual de los públicos, es decir, una reflexión que apela al análisis de los públicos en el marco de los procesos en los que la participación cultural 
tiene lugar. Entender a los públicos como procesos implica ampliar los momentos constitutivos de la experiencia cultural, abriendo la mirada a todo aquello que sucede no solo en el consumo, sino también a partir de este. Más allá de la interacción efímera entre los públicos y los bienes y servicios culturales, resulta preciso indagar en los efectos que estos tienen en la vida de las personas, en la medida en que desempeñan roles significativos en la construcción de identidades y subjetividades.

La recepción de los bienes simbólicos no puede ser observada como la interacción solitaria entre individuos y productos (Campos, 2012), sino que debe ser interpretada en el marco de una amplia red de relaciones sociales involucradas directa o indirectamente en el consumo cultural. No solo porque la inmensa mayoría de los usuarios de los bienes culturales efectúan estos "consumos" en compañía de otros individuos, sino que también porque, de acuerdo a los estudios realizados por el PNUD (2002), existe una afinidad electiva - un vínculo entre dos dinámicas sociales diferentes, dada la similitud de sus sentidos subjetivos y finalidades (Güell, Morales y Peters, 2012) - entre el consumo cultural y una serie de actitudes y valores vinculados a la asociatividad, confianza hacia las personas y apertura a la diversidad (Güell, Godoy y Frei, 2005). En la misma línea, dicha afinidad electiva también se establece entre el consumo cultural y las formas de sociabilidad, puesto que los sujetos que declaran un mayor nivel de convivencia amistosa y de capital social, son también los que más acceden a bienes y servicios culturales (Peters, 2012).

Como ha apuntado Néstor García Canclini (2014) al observar las dinámicas de las ferias de libros contemporáneas, mientras la piratería y la reproducción digital hacen peligrar las cifras de las disqueras y editoriales, este tipo de eventos parece cobrar una fuerza inusitada, poniendo de manifiesto que en el ejercicio de la vida cultural se ponen en juego nuevos modos de presencialidad y sociabilidad. La oferta artística y cultural constituye, en este sentido, un buen vehículo para formas renovadas del "estar juntos", e incluso prácticas que, como la lectura, tradicionalmente se asumían solitarias e introspectivas, cobran significado sobre todo cuando se comparten y activan comunidades de circulación e intercambio. Este nivel "conversacional" de las prácticas culturales se manifiesta de manera clara a través del uso contemporáneo de las nuevas tecnologías, tal y como lo demuestran Leveratto y Leontsini (2008) en su estudio acerca de internet y la "sociabilidad literaria".

Esta tercera categoría de pregunta, sin duda la más compleja, ha sido la menos abordada hasta el momento. Proponemos que justamente en esta 
dirección debe apuntar el debate en torno a los públicos culturales y sus estrategias de estudio, para entender cómo las prácticas de consumo cultural pueden ser menos cifras de taquilla y más experiencias ciudadanas. Planteamos, entonces, que los estudios de los públicos de la cultura se diferencian de los estudios de los visitantes y de las audiencias, porque ya no se preocupan tanto por las variables sociodemográficas del acceso, ni por las condiciones de interpretación de los bienes culturales, sino que -sobre todo- se interrogan por los efectos que tienen las obras expuestas sobre los procesos de interpretación y apropiación en el marco de la vida social.

Avanzar desde los estudios de visitantes hacia los estudios de público implica romper con una serie de preconcepciones. Existen al menos tres supuestos que han marcado especialmente el devenir de los estudios sobre públicos culturales: una noción de externalidad entre los sujetos y las ofertas culturales; una concepción del campo como espacio clausurado sobre sí mismo; y una visión ahistórica y sincrónica respecto de los procesos de participación cultural. El primero de estos supuestos opera aislando como variables independientes ciertos elementos que forman parte de relaciones sociales intrincadas, arrojando una visión estática e incompleta de los procesos de consumo cultural. Sostenemos aquí que es preciso examinar los modos específicos en los que las audiencias y estos productos se constituyen recíprocamente. El segundo supuesto, la clausura, tal vez una herencia de los estudios de Bourdieu, sigue pensando a estos usuarios como portadores de un interés específicamente cultural hacia las obras de arte o el patrimonio, dando escasa importancia en el análisis a otras motivaciones posibles, aún en tiempos marcados por la convergencia de muchos contenidos simultáneos. Hoy las fronteras entre acceso y exclusión, normalmente definidas a partir de criterios espaciales o materiales objetivos, se hacen cada vez más difusas: también hay cine en las pantallas de los buses y poesía en las paredes de la ciudad. Finalmente, el tercer supuesto que ha caracterizado los estudios sobre públicos guarda relación con una mirada ahistórica y sincrónica, que no considera debidamente los efectos de las trayectorias de los individuos en sus relaciones con la oferta cultural. Se suelen considerar unidades de tiempo cerradas sobre sí mismas: las encuestas preguntan por las actividades culturales visitadas en "el último año", y los estudios sobre percepción y evaluación de la cultura se centran en una exposición o evento específico. Aun cuando es atendible que los recursos de investigación sean limitados, esta estrecha perspectiva sobre el ciclo cultural descansa también en la idea de que los individuos se relacionan con la oferta cultural a partir de un habitus muy estable, que permite proyectar las prácticas de 
consumo de un sujeto tanto hacia el pasado como hacia el futuro. Si las evidencias apuntan en otro sentido, se buscan respuestas en transformaciones externas a los sujetos (cambios en la oferta o políticas de acceso), y no en el efecto de sus propias experiencias. Entre otras cosas, esto limita la capacidad de los estudios para observar el impacto que la participación cultural tiene sobre la propia participación cultural. Sostenemos que resulta preciso investigar la constitución recíproca de públicos, ofertas culturales y formas de investigación de estos, considerando el carácter dinámico e inestable de estos procesos. Así como las miradas acerca de los públicos se transforman e incorporan elementos de diversas tradiciones, también los sujetos que conforman esos públicos constituyen una realidad en transformación, que explora nuevas formas de relacionarse con los bienes culturales y se debate entre modos diversos de enmarcar la experiencia cultural.

\section{LA CENTRALIDAD DE LAS PRÁCTICAS COMO LUGAR DE LA EXPERIENCIA CULTURAL}

Como hemos detallado en textos recientes (Güell, Peters y Morales, 2012; Güell, 2012), los fenómenos sociales contemporáneos nos exigen pensar los públicos desde otros supuestos, que permitan imaginar la experiencia cultural en el cruce de una doble apertura: la apertura de las identidades individuales, y la apertura de los significados de los bienes culturales. Si asumimos que los sujetos no constituyen realidades acabadas e inmutables, y que los bienes simbólicos se muestran ambivalentes y dispuestos para apropiaciones diversas, resulta preciso abrir el análisis a un espacio indeterminado de influjos: el ámbito de las prácticas.

Proponemos que los públicos culturales, en tanto sujetos de una experiencia, deben ser estudiados como efectos o resultados de prácticas significativas realizadas en los espacios y tiempos de las ofertas culturales. La investigación sobre las experiencias culturales debe poner atención en los procesos de subjetivación que emergen de las prácticas culturales, y no ya como producto de subjetividades preexistentes. Esto no significa que no haya variables independientes, identidades o factores anteriores que condicionan las dinámicas de los públicos; solo quiere decir que ellas no bastan para explicarlas, pues sus significados y efectos están mediados en el contexto de las prácticas culturales concretas. Y esto no solo ocurre por el lado de los individuos, también ocurre por el lado de la oferta cultural. Las prácticas efectivas del consumo cultural no solo redefinen -por la vía 
de las evaluaciones institucionales- la propia forma concreta, la oferta y los mensajes de las instituciones de la cultura, sino que también definen el significado y el efecto que ellas tienen en el espacio público. Visto desde la perspectiva de las prácticas culturales, no solo los públicos y audiencias hacen experiencias, también las hacen las instituciones y sus actores.

Así, la doble apertura entre los públicos y la oferta de las instituciones culturales se resuelve en una práctica dinámica: cada práctica específica genera una experiencia, que a su vez genera las bases para los siguientes desarrollos de esa práctica. Una práctica cultural entendida como espacio y tiempo de experiencias puede ser vista como una constelación de fuerzas y factores que condicionan el trabajo que cada uno hace para cerrar la doble apertura de la propia identidad y del significado del bien cultural. ¿Qué significa, entonces, estudiar las prácticas significativas que tienen lugar en los tiempos y espacios de las ofertas culturales? Significa estudiar interacciones. Y no se trata exclusivamente de interacciones entre individuos, o entre individuos y ciertos bienes culturales, sino entre las lógicas que ponen en juego cada uno de ellos. Lo que importa es el efecto de la interacción entre esas lógicas a nivel de la experiencia subjetiva y a nivel de sus consecuencias sociales.

No cabe duda de que los estudios de visitantes continúan siendo un aporte. La mirada estadística y sociodemográfica seguirá siendo provechosa y necesaria para este campo de investigación, sobre todo puesto que la intolerable brecha de acceso cultural persiste en América Latina. Las encuestas nacionales de consumo cultural han hecho grandes avances y están aportando valiosa información seriada. Tal vez estos estudios pueden ganar capacidad explicativa revisando los indicadores que definen los bienes culturales y las variables que gradúan la medición del acceso, con el objeto de dar cabida a los nuevos fenómenos y actores culturales. El avance de este tipo de trabajos cuantitativos debe conjugar, de este modo, innovación y comparabilidad, fomentando el desarrollo de espacios de coordinación iberoamericanos.

Los estudios de audiencias, es decir, la observación de las experiencias culturales a nivel de la subjetividad individual, enfrentan desafíos importantes. El análisis del "marco de interpretación" de las audiencias suele realizarse a partir de las diferencias entre los grupos como entidades acabadas, sin tomar en consideración que las experiencias se constituyen precisamente en la práctica. Así, en muchos casos, se levantan datos cualitativos para analizarlos desde una lógica cuantitativa; esto es, pensando que la identidad de un individuo está en su diferencia con otros individuos, y que entre 
ellos los datos solo muestran diferencias de grado, pero no de sentido. Pensamos que este tipo de estudios puede enriquecerse con ciertos recursos de la etnografía -desde la atención a la gestualidad corporal hasta el estudio de los rituales- convocando preguntas que involucran los usos del cuerpo, los estados emocionales, las asociaciones simbólicas y otros repertorios de acción que tienen lugar en estas prácticas de consumo cultural. Será preciso, además, avanzar hacia la elaboración de tipologías de estas experiencias, que permitan el diálogo comparativo entre distintas instancias artísticas y diversas localidades.

Los estudios de públicos, en el sentido específico que les hemos dado en este texto, quieren llamar la atención sobre el hecho de que los efectos de estas experiencias culturales no se limitan a los individuos, sino que también impactan las relaciones sociales. Las experiencias culturales no están completas si no consideramos cómo se transforman en interacciones comunicativas: conversaciones, debates, conflictos, etc. De este modo, las etnografías de sala debieran registrar la presencia o ausencia de esos intercambios, el tipo de "otros" -anónimos o conocidos- que involucra y, de ser posible, mediante la observación participante, los temas de conversación. Y si estudiar el efecto de las experiencias culturales en el terreno de las conversaciones posteriores puede resultar demasiado complejo, lento o caro, rastrear su evolución a través de las redes sociales y foros digitales -extensión contemporánea de aquellas instancias de sociabilidad- parece estar siendo una alternativa fructífera.

A pesar de las dificultades que tiene estudiar el efecto subjetivo y público de las experiencias culturales, es probable que esta sea la dirección que debamos transitar en el mediano plazo. La idea de democratización de la cultura, entendida como superación de las barreras de acceso, no recoge ya todas las demandas por democratización, como aquellas que se dirigen a la participación activa en la creación o a la valoración de las diferencias. Crecientemente, el desafío más importante en la relación entre políticas culturales y democracia no es tanto la igualdad en el acceso a la cultura, sino dotar de sentido cultural a la democracia, es decir, vincularla a las experiencias cotidianas. Los esfuerzos de "democratización de la cultura", en este sentido, deberán ser complementados por los de una "culturización de la democracia".

Los desafíos que impone una investigación de los públicos son numerosos y, por lo mismo, el estudio de la contextura y el efecto social de las experiencias culturales posiblemente dependa de muchos esfuerzos aunados. Es preciso desplegar técnicas de largo aliento para aprehender el carácter 
histórico, dinámico, abierto y contextualmente situado de estas formas de experiencia. Sabemos que encontraremos en ellas una compleja trama de condicionamientos institucionales y subjetivos, de formas diferenciadas de poder y de agencia, que se dejan sentir en diversos niveles de la experiencia cultural: emocional, reflexiva y comunicativamente. Hay todavía mucho por descubrir en estos territorios, y será preciso activar nuevas formas de imaginación sociológica para dar con las técnicas y herramientas metodológicas más apropiadas para comprender estos fenómenos. Desde nuestra perspectiva, sin embargo, no son los métodos los que precisan de atención con mayor urgencia: una vez que hemos encontrado los problemas y las definiciones correctas, no nos costará trabajo dar con ellos.

\section{REFERENCIAS}

Anderson, M. (2004). Metrics of success in art museums. Getty Leadership Institut. Recuperado de : http://isites.harvard.edu/fs/docs/icb.topic974245. files/Accountability\%20Sept $\% 2012 /$ metrics $\% 20$ of $\% 20$ success $\% 20$ in $\% 20$ art\%20museums.pdf

Bourdieu, P. (2012). La distinción. Criterio y bases sociales del gusto. Ciudad de México: Taurus.

Bourdieu, P. y Darbel, A. (2003). El amor al arte. Los museos europeos y su público. Barcelona, España: Paidós Estética.

Campos, L. (2012). El consumo cultural: una actividad situada. En P. Güell y T. Peters (eds.). La trama social de las prácticas culturales (pp. 51-81). Santiago: Universidad Alberto Hurtado.

Castilla, A. (2010). El museo en escena. Política y cultura en América Latina. Buenos Aires, Argentina: Paidós/Fundación TyPA.

Cimet, E. (1987). El público como propuesta. Cuatro estudios sociológicos en museos de arte. Ciudad de México: Cenidiap-INBA.

Fox, H. (2006). Beyond the Bottom Line: Evaluating Art Museums with the Balanced Scorecard. Getty Leadership Institut. Recuperado de: http://citeseerx. ist.psu.edu/viewdoc/download?doi=10.1.1.615.5506\&rep=rep $1 \&$ type=pdf

García Blanco, A., Pérez Santos, E., y Andonegui, M. O. (1999). Los visitantes de museos: Un estudio de público en cuatro museos. Madrid, España: Ministerio de Educación y Cultura.

García Canclini, N. (2004). Diferentes, desiguales y desconectados. Mapas de la interculturalidad. Barcelona, España: Gedisa.

García Canclini, N. (2014). Las ferias en una época en que se venden menos libros y se lee más. Ciudad de México, Inédito. Manuscrito facilitado por el autor. 
Garde L., V. y Varela A., E. (2010). ¿Al servicio de la sociedad y de su desarrollo? El Laboratorio Permanente de Públicos de Museos: una herramienta de gestión. En Museos.es (5-6). Ministerio de Cultura, España, pp. 208-221.

Güell, P., Godoy, S. y Frei, R. (2005). El consumo cultural y la vida cotidiana: algunas hipótesis empíricas. En: C. Catalán y P. Torche (eds.). Consumo cultural en Chile. Miradas y perspectivas (pp. 77-88). Santiago de Chile: INE- CNCA.

Güell, P., Morales, R. y Peters, T. (2012). Individuación y consumo cultural: las afinidades electivas. En: P. Güell y T. Peters (eds.). La trama social de las prácticas culturales (pp. 21-49). Santiago de Chile: Universidad Alberto Hurtado.

Hannerz, U. (1996). Conexiones transnacionales: cultura, gente, lugares. Valencia, España: Cátedra/Universidad de Valencia.

Heinich, N. (2001). La sociología del arte. Buenos Aires, Argentina: Nueva Visión.

Holo, S. y Álvarez, M. (2011). Más allá de la taquilla. Defendiendo a los museos $y$ sus valores sustentables. Ciudad de México: MUAC/UNAM.

Hood, M. (1986). Gettingstarted in AudienceResearch. Museum News 2, 25-31. Huyssen, A. (1994). De la acumulación a la mise en scène: el museo como medio masivo. Criterios, La Habana, 31, 151-176.

Iregui, J. (2008). El museo fuera de lugar. Bogotá, Colombia: Universidad de los Andes.

Leveratto, J. M. y Leontsini, M. (2008). Internet et la sociabilité littéraire. París: Array. Disponible en: http://books.openedition.org/bibpompidou/197

Ochoa, A. M. (2003). Entre los deseos y los derechos. Un ensayo crítico sobre políticas culturales. Bogotá, Colombia: Instituto Colombiano de Antropología e Historia.

Ojeda Sánchez, C. (2008). La visita al museo como experiencia. Metodología para la medición del grado de satisfacción del visitante. Mus-A. Revista de los Museos de Andalucía, Año VI (10), 58-67.

Olivera, E. (2011). Recepción estética/ públicos plurales. En: José Jiménez (ed.). Una teoría del arte desde América Latina (pp. 214-234). Madrid, España: MEIAC/ Turner.

Pérez Santos, E. (2008). Metodología básica de la investigación de públicos de museos. Variables implicadas, tipos de investigaciones y técnicas utilizadas. Mus-A. Revista de los Museos de Andalucía, 10, 48-57.

Peters, T. (2012). La afinidad electiva entre consumo cultural y percepción sociocultural: el caso de Chile. En: Güell, P. y Peters, T. (eds.). La trama social de las prácticas culturales (pp. 149-177). Santiago de Chile: Universidad Alberto Hurtado.

PNUD (2002). Nosotros los chilenos. Un desafío cultural. Informe de desarrollo humano. Santiago de Chile. 
Rosas Mantecón, A. (2007). Barreras entre los museos y sus públicos en la Ciudad de México. Revista Culturales, III(5), 79-104.

Schmilchuk, G. (2012). Públicos y museos, agentes de consumo y sujetos de experiencia. Alteridades, 44, 23-40.

Verón, E., y Levasseur, M. (1991). Ethnographie de l'éxposition, París, Francia: Centre Georges Pompidou.

Wimmer, A. y Vericat, I. (2000). La cultura como concertación. Revista Mexicana de Sociología, 62(4), 27-157.

Yúdice, G., y Miller, T. (2004). Política cultural. Barcelona, España: Gedisa. 